\title{
Optimal Ramsey Capital Taxation with Endogenous Government Spending
}

\author{
$\underline{\text { YiLi Chien and Junsang Lee }}$
}

\begin{abstract}
The authors study optimal capital income taxation in heterogeneous agent economies featuring endogenous government spending. Similar to Aiyagari (1995), they find that the long-run optimal capital tax rate should not be zero as long as the competitive equilibrium risk-free interest rate differs from the subjective time discount rate. The authors first argue that this result holds in a wide range of economic environments and is not limited to only the standard incomplete market model with heterogeneous agents. As an example, a decentralized economy with limited commitment is considered. Second, they show that this result critically depends on the assumption of endogenous government spending. Within the same limited commitment environment, they show that the long-run capital taxation becomes zero with exogenous government spending. The authors conclude that the optimal Ramsey taxation in heterogeneous agent economies with exogenous government spending and various frictions is still an open question. (JEL C61, E22, E62)
\end{abstract}

Federal Reserve Bank of St. Louis Review, Fourth Quarter 2016, 98(4), pp. 311-27.

http://dx.doi.org/10.20955/r.2016.311-327

\section{INTRODUCTION}

Academic researchers and policymakers have shown interest in how to design an optimal taxation system in an economy. The question of optimal taxation focuses on how fiscal authorities use their available policy tools (e.g., taxation) to minimize welfare loss while meeting the need for government expenditure. In the public finance literature, the approaches for solving the optimal taxation problem depend on the assumptions of what policy tools are available. One major approach, the so-called Ramsey approach (Ramsey, 1927), considers a limited set of tools that the government can use in setting up the tax system. ${ }^{1}$ Particularly, the approach assumes that the government, also called the Ramsey planner, can finance its expenditures only by levying distortionary linear taxes. In addition, the government considers the reaction of market participants (e.g., households and firms) when designing the optimal taxation sys-

YiLi Chien is a senior economist at the Federal Reserve Bank of St. Louis. Junsang Lee, the corresponding author, is an associate professor of economics at Sungkyunkwan University. Junsang Lee acknowledges support from the Ministry of Education of the Republic of Korea and the National Research Foundation of Korea (grant no. NRF-2015S1A5A8017935). The authors thank Paul Morris for research support.

(c) 2016, Federal Reserve Bank of St. Louis. The views expressed in this article are those of the author(s) and do not necessarily reflect the views of the Federal Reserve System, the Board of Governors, or the regional Federal Reserve Banks. Articles may be reprinted, reproduced, published, distributed, displayed, and transmitted in their entirety if copyright notice, author name(s), and full citation are included. Abstracts, synopses, and other derivative works may be made only with prior written permission of the Federal Reserve Bank of St. Louis. 


\section{Chien and Lee}

tem. A Ramsey problem is therefore referred to as a constrained maximization problem for designing the optimal taxation system. In the problem, the Ramsey planner maximizes the social welfare of an economy by choosing a limited set of tax instruments while satisfying a set of constraints. These constraints guarantee that the optimal tax system should be compatible with the optimal reactions of market participants.

In the literature on Ramsey taxation, one of the most famous results (and a very surprising one) shown by Chamley (1986) and Judd (1985) is that the long-run capital tax rate should be zero. That is, taxing capital is a bad idea for an economy and the welfare cost of capital taxation is so high that the tax rate has to be zero at least in the long run. The intuition actually comes from an earlier work by Diamond and Mirrlees (1971), who suggest that the intermediate inputs, such as capital, should not be taxed. Chari and Kehoe (1999) further show that the capital tax rate can be high initially but should decrease to zero over the transition. In addition, Atkeson, Chari, and Kehoe (1999) show that the zero capital taxation result is robust to a wide range of the model assumptions. These results have strong implications for the current tax policy since they suggest that (i) the current capital tax rate is too high and (ii) decreasing the tax rate can lead to large welfare gains as Lucas (1990) suggests.

Aiyagari's (1995) study is the first attempt to investigate whether the zero capital taxation result obtained from a representative agent model is still robust to an incomplete market economy with heterogeneous agents, which is the economy considered in Aiyagari (1994) (the Aiyagari economy hereafter). This question is very important because the Aiyagari economy can account for a great deal of consumption and wealth heterogeneity observed in data. Hence, the Aiyagari economy has been widely used for policy evaluation, especially for considering the distributional effects of policy changes.

In contrast to the zero capital taxation literature, Aiyagari (1995) argues that the optimal capital tax rate could be positive in the long run in an economy with heterogeneous agents. This nonzero capital taxation builds on two findings from the Aiyagari economy. First, "oversaving" exists in such an incomplete market economy. Households cannot hedge against their idiosyncratic income risks and, hence, have a precautionary saving motive to smooth their consumption stream over time. 2 As a result, the capital level in a laissez-faire competitive equilibrium exceeds the level in a representative agent economy. Second, the optimal steadystate capital level chosen by the Ramsey planner is the same as in the representative agent economy even in an incomplete market environment. Therefore, from the view of the Ramsey planner, there is an overinvestment in capital stocks caused by the precautionary savings. The capital taxation serves to lower the capital level back to its optimal level.

Aiyagari's (1995) results are derived from the inconsistency of the Euler equations between the one chosen by the Ramsey planner and the one that emerges in the competitive equilibrium. The Euler equations characterize the optimal choice of capital investment in the intertemporal margins and, hence, there is a corresponding optimal capital level to each Euler equation. The Ramsey planner chooses the optimal capital level that satisfies a specific Euler equation - the so-called modified golden rule (MGR) - in steady state. The MGR indicates that the intertemporal shadow price equating the marginal benefit and marginal cost of capital investment should be equal to the time discount rate, denoted by $1 / \beta$, where $\beta$ is the time 
discount factor. However, the intertemporal equilibrium price, which is the risk-free interest rate, $R$, can be shown to be a value lower than $1 / \beta$ because of the precautionary saving motivation. The discrepancy of intertemporal prices between the Ramsey planner and the competitive equilibrium motivates and induces a positive capital taxation in the Aiyagari economy.

An interesting and important observation is that both the representative agent economy and the Aiyagari economy find the same level of capital stock as socially optimum in the steady state, where the MGR is satisfied in both economies. However, the implication of the tax policy is completely opposite because the market equilibrium intertemporal prices are different. In the zero capital taxation literature, the market equilibrium reaches the optimal capital level implied by the MGR, so there is no need for the Ramsey planner to tax capital. On the other hand, in the Aiyagari economy, the precautionary savings result in an equilibrium capital stock higher than that implied by the MGR, so an optimal capital tax needs to reduce the capital to its optimal level.

In this article, we first show that the positive capital taxation results obtained by Aiyagari (1995) can be extended to a wide range of model economies. We show that the socially optimal level of steady-state capital stock should still satisfy the MGR among these model economies. The idea and intuition can be seen by the following. The Ramsey planner chooses the optimal capital stock at its intertemporal margin. The margin is set by considering the intertemporal marginal benefit and the cost of having one extra unit of capital investment. Under the assumption of endogenous government spending, the planner can finance the extra unit of capital investment by reducing the same amount of government spending while holding all other variables unchanged. $\underline{-}$ The marginal cost of capital investment is therefore the marginal utility of government spending, which is assumed to be identical across heterogeneous households. In the next period, the additional output produced by the one extra unit of investment is the marginal product of capital plus the amount of capital net of depreciation. The planner can raise government spending to exactly offset the extra resources available so that all other variables remain the same in this subsequent period. At the optimum, the marginal benefit and the cost of capital investment have to be equal, which leads to the MGR in steady state. Importantly, the derivation of the MGR in a Ramsey problem for the optimal capital level has nothing to do with the specific market frictions in the Aiyagari economy. Hence, the same result should carry through in other model economies as well. Our conjecture is that equilibrium allocations with a capital level higher than that satisfied by the MGR can induce a positive capital taxation in the steady state.

We therefore provide a generic description of a class of models that can yield the same result as in Aiyagari (1995). In our generic model, the Ramsey planner always chooses the optimal capital level as the one that satisfies the MGR in steady state regardless of the ingredients in market frictions. Essentially, this result provides a rationale for a positive capital taxation: A model with the market intertemporal price, $R$, lower than $1 / \beta$ can be used to motivate positive capital taxation. One can actually relate this rationale to the question posed in the asset pricing literature: Why is the market risk-free interest rate lower than the time discount rate? The macroeconomic models whose risk-free market interest rate is below $1 / \beta$ in a competitive equilibrium would imply a positive optimal capital tax. 
Second, we also show that our result builds on a key assumption that the Ramsey planner can choose a level of government spending endogenously in addition to the optimal tax rates, which is a nonstandard assumption in the Ramsey literature. With exogenous government spending, the Ramsey planner does not necessarily choose the same level of capital stock that satisfies the MGR in steady state. Consider that the Ramsey planner makes a variation of one extra unit of capital investment as mentioned previously. Without endogenous government spending, the planner can no longer offset the extra unit of investment by reducing government spending. Instead, the extra unit of capital investment results in one unit of reduced aggregate consumption to satisfy the resource constraint. In this case, the marginal cost of having one extra unit of investment is equal to the welfare cost of reducing one unit of aggregate consumption, which depends on the distribution of consumption in a heterogeneous agent economy. On the benefit side of this variation, the extra unit of investment leads to higher output in the next period and this extra aggregate output should be consumed by households, not by the government. The marginal benefit is therefore equal to the welfare benefit of all households consuming the extra units of output.

In the heterogeneous agent economy, it is not necessarily the case that the benefit of having one extra unit of output is identical over time even in the long run. Therefore, because of the uneven evaluation of extra output over time, the optimal intertemporal price could deviate from $1 / \beta$, which is the one implied by the MGR. In Aiyagari (1995), on the other hand, the marginal benefit of extra output has to be constant in the long run because all households can receive the same amount of extra utility from the output, used as government spending. Household heterogeneity plays no role in deciding the optimal level of capital. The marginal benefit of having one extra unit of output faced by the planner is identical across the population and over time in steady state as in the representative agent economy. This is the mechanism through which the optimal Ramsey capital allocation is the same as in the representative agent economy, which satisfies the MGR.

To demonstrate our second argument clearly, we provide an example in which we show that the optimal capital tax is positive with an assumption of endogenous government spending but becomes zero with exogenous government spending. This example considers a complete market economy with limited commitment: Households are able to trade a full set of state-contingent claims such that they can hedge themselves fully against idiosyncratic shocks. However, households cannot promise to repay their debts and can default on their existing debts if default is in their interest. Upon default, households would be excluded from future trading of financial assets and receive an exogenously given autarky value. This example is similar to Park's (2014) benchmark model except for the exogenously given autarky value upon default. Given this environment, we show that the risk-free rate in a laissez-faire competitive equilibrium is lower than the time discount rate. Hence, the capital taxation should be positive given the assumption of endogenous government spending. With exogenous government spending, however, we demonstrate that the optimal capital tax rate should become zero.

In sum, we argue that the question of optimal Ramsey taxation in the Aiyagari economy is still open. Without the assumption of endogenous government spending, the evaluation of 
adding one extra unit of aggregate consumption involves a complicated function that would depend on the entire sequence of consumption and labor distributions. Obviously, the evolution of these distributions also depends on the specific assumptions regarding market structures and frictions in a model economy. Analyzing the evolution of the distributions is not an easy task. We suspect the optimal taxation result should be varied according to the specific assumptions for the source of heterogeneity and market structures.

This article is organized as follows. Section 2 describes the generic model economy. Section 3 solves a Ramsey problem and discusses the optimal capital income tax in steady state. In Section 4, we show that in an economy with limited commitment, the capital taxation result depends critically on the assumption of endogenous government spending. Section 5 concludes with remarks on the issues relating these theoretical results to the actual tax policy.

\section{THE GENERIC MODEL}

We first introduce a generic model where the optimal level of capital stock satisfies the MGR in a steady state. The essential idea is similar to that in Aiyagari (1995). To show the result, we remove assumptions that are not pivotal to the MGR result and keep our generic model as simple as possible.

\subsection{Environment}

Time is discrete. There is a continuum of households of measure one. Each household starts with an initial asset holding, $a_{0}$, and an initial idiosyncratic shock, $s_{0}$. The initial joint distribution over $\left(a_{0}, s_{0}\right)$ is given by $\Phi_{0}$ In this article, we do not consider the aggregate shock. The only event each household faces is an idiosyncratic stochastic shock. When we consider the specific model example later (see Section 4), the actual idiosyncratic stochastic shock is to be specified. Each event $s_{i}$ takes values on a discrete grid $S \equiv\left\{s_{1}, \ldots, s_{i}, \ldots, s_{I}\right\}$. The shock $\{s\}$ follows a Markov process with a transition probability $\pi\left(s^{\prime} \mid s\right)$. We denote $s^{t}$ as a history of the shock:

$$
s^{t}=\left(s_{0}, s_{1}, \ldots, s_{t-1}, s_{t}\right) .
$$

There is a single, nonstorable consumption good. A household's preference is described by the expected value of the sum of discounted utilities of consumption and labor streams plus the expected utility derived from government spending:

$$
\sum_{t=0}^{\infty} \sum_{s^{t}} \beta^{t} U\left(c_{t}\left(s^{t}\right), l_{t}\left(s^{t}\right)\right) \pi\left(s^{t} \mid s_{0}\right)+\sum_{t=0}^{\infty} \beta^{t} V\left(G_{t}\right)
$$

where $c_{t}, l_{t}$, and $G_{t}$ denote household consumption, the household labor supply, and aggregate government spending, respectively. $\beta$ is a subjective discount factor. The functions $U(\cdot, \cdot)$ and $V(\cdot)$ are assumed to be bounded, continuously differentiable, strictly increasing, and strictly concave.

The output $Y_{t}$ is produced by aggregate labor and capital input with a single technology that exhibits constant returns to scale: 


$$
Y_{t}=F\left(K_{t}, L_{t}\right)
$$

where $F(\cdot, \cdot)$ is the market production function, and $K_{t}$ and $L_{t}$ denote aggregate capital and aggregate labor inputs, respectively. Assume that $F(\cdot, \cdot)$ is homogeneous of degree one and twice continuously differentiable.

The output can be used in aggregate consumption, $C_{t}$; government spending, $G_{t}$; or net capital investment, $K_{t+1}-(1-\delta) K_{t}$. The resource constraint is

$$
C_{t}+G_{t}+K_{t+1}-(1-\delta) K_{t}=Y_{t} \text {, }
$$

where $\delta$ denotes the capital depreciation rate.

\subsection{The Firm's Problem}

At period 0, taking a sequence of pretax wage rates $\left\{w_{t}\right\}_{t=0}^{\infty}$, market interest rates $\left\{R_{t}\right\}_{t=0}^{\infty}$, and capital income taxes $\left\{\tau_{K, t}\right\}_{t=0}^{\infty}$ as given, a firm chooses a sequence of capital stocks $K_{t+1}$ and labor demand $L_{t}$ to maximize the discounted after-tax profit function:

$$
\max _{\left\{K_{t+1}, L_{t}\right\}} \sum_{t} \prod_{j=1}^{t} \frac{1}{R_{j-1}}\left[\left(1-\tau_{K, t}\right) \varphi_{t}-I_{t}+\delta \tau_{K, t} K_{t}\right],
$$

subject to

$$
\begin{aligned}
& \varphi_{t}=F\left(K_{t}, L_{t}\right)-w_{t} L_{t} \\
& K_{t+1}=(1-\delta) K_{t}+I_{t},
\end{aligned}
$$

where $\varphi_{t}$ is a corporate profit. Note that firms pay the capital income tax, which is imposed on the income earned from the physical capital. $\underline{4}$

The firm's problem yields the following first-order conditions:

$$
\begin{aligned}
& w_{t}=F_{L, t} \\
& 1=q_{t}\left[\left(M P_{K, t+1}-\delta\right)\left(1-\tau_{K, t+1}\right)+1\right],
\end{aligned}
$$

where $q_{t} \equiv \frac{1}{R_{t}}$ is an intertemporal price and $M P_{K}$ is the marginal product of capital. Based on these optimal conditions, firms make decisions on labor demand and capital investment.

\subsection{The Household's Problem}

As we will show clearly, the optimal Euler equation chosen by the Ramsey planner does not rely on the specific frictions faced by the households as long as the household indirect utility function can be written as a function of initial conditions and a sequence of equilibrium prices that can be controlled by tax policies. Hence, we ignore the specific details of the household problem in this generic model. In period 0 , taking the sequence of after-tax wages $\left\{\bar{w}_{t} \equiv\left(1-\tau_{L, t}\right) w_{t}\right\}_{t=0}^{\infty}$, the market interest rates $\left\{R_{t}\right\}_{t=0}^{\infty}$, and government spending $\left\{G_{t}\right\}_{t=0}^{\infty}$ as given, a household chooses a sequence of consumptions and labors $\left\{c_{t}\left(s^{t}\right), l_{t}\left(s^{t}\right)\right\}_{t=0}^{\infty}$ that maximizes 
the agent's lifetime utility subject to the household's constraints. $\frac{5}{}$ Once we solve this household's maximization problem, then the indirect utility function of a household with initial states $\left(a_{0}, s_{0}\right)$ can be written as

$$
W_{0}\left(a_{0}, s_{0},\left\{\bar{w}_{t}\right\}_{t=0}^{\infty},\left\{R_{t}\right\}_{t=0}^{\infty}\right) \text {, }
$$

which is a function of the initial state and the sequence of prices.

\subsection{The Government}

The government levies a linear tax on capital and labor incomes and issues new government bonds to finance endogenous government spending and outstanding government debt. Government expenditure is composed of an endogenous government consumption, $G_{t}$, and debt payments, $R_{t} B_{t}$. Government revenue consists of taxes on market labor income and capital income. Additionally, the government can finance its expenditures by issuing new debt, $B_{t+1}$ Hence, the government constraint is as follows:

$$
\tau_{K, t} \varphi_{t}+\tau_{L, t} w_{t} L_{t}+B_{t+1}=R_{t} B_{t}+G_{t}
$$

\subsection{Competitive Equilibrium}

Definition 1 Given initial conditions $K_{0}$ and $B_{0}$ and a sequence of policies $\left\{\tau_{L, t}, \tau_{K, t}, B_{t+1}, G_{t}\right\}, a$ competitive equilibrium is a sequence of allocations $\left\{c_{t}\left(a_{0}, s^{t}\right), l_{t}\left(a_{0}, s^{t}\right), K_{t+1}\right\}$ and prices $\left\{w_{t}, R_{t}\right\}$ such that the household's problem is solved for each household with initial condition $\left(a_{0}, s_{0}\right)$, the firm's problem is solved, the government budget constraint is satisfied for all periods, and all markets clear.

\section{OPTIMAL RAMSEY TAXATION}

\subsection{The Ramsey Problem}

Following Aiyagari (1995), we formulate a dual-approach Ramsey problem such that the government can pick the sequences of $\left\{\bar{w}_{t}, R_{t}, G_{t}, K_{t+1}\right\}$. First, the social welfare function is the sum of the integration of all households' lifetime utility over the initial distribution $\Phi_{0}$ and the discounted utility from government spending, so this social welfare function depends on the sequence of $\left\{\bar{w}_{t}, R_{t}, G_{t}\right\}$. Second, by choosing the sequence of $R_{t}, G_{t}$, and $K_{t+1}$ together with equation (2), the capital tax sequence can be decided. In addition, the labor tax sequence is decided by $\bar{w}_{t}=\left(1-\tau_{L, t}\right) w_{t}$. Note that the optimal choices of consumption, labor, and the household's budget constraint are embedded in the indirect utility function expressed in equation (3). Hence, the government's optimal tax problem is to choose sequences of $\left\{\bar{w}_{t}, G_{t}, K_{t+1}\right\}$ and a sequence of $\left\{R_{t}\right\}$ that are consistent with the competitive equilibrium such that social welfare is maximized as follows:

$$
\max _{\left\{\bar{w}_{t}, R_{t}, G_{t}, K_{t+1}\right\}} \int W_{0}\left(a_{0}, s_{0},\left\{\bar{w}_{t}\right\}_{t=0}^{\infty},\left\{R_{t}\right\}_{t=0}^{\infty}\right) d \Phi_{0}+\sum_{t=0}^{\infty} \beta^{t} V\left(G_{t}\right)
$$




\section{Chien and Lee}

subject to

$$
C_{t}+K_{t+1}+G_{t}=F\left(K_{t}, L_{t}\right)+(1-\delta) K_{t}
$$

Equation (4) is the resource constraint and must hold for all periods. Note that as is generally the case in Ramsey problems, we exclude the government budget constraint because household consumption choices satisfy the household's budget constraints, which together with the resource constraints imply the government budget constraints.

The Lagrangian is written as

$$
\begin{aligned}
& L_{G}=\min _{\mu_{t}} \max _{\left\{\bar{w}_{t}, R_{t}, G_{t}, K_{t+1}\right\}} \int W_{0}\left(a_{0}, s_{0},\left\{\bar{w}_{t}\right\}_{t=0}^{\infty},\left\{R_{t}\right\}_{t=0}^{\infty}\right) d \Phi_{0}+\sum_{t=0}^{\infty} \beta^{t} \mathrm{~V}\left(G_{t}\right) \\
& +\sum_{t=0}^{\infty} \beta^{t} \mu_{t}\left(F\left(K_{t}, L_{t}\right)+(1-\delta) K_{t}-C_{t}-K_{t+1}-G_{t}\right),
\end{aligned}
$$

where $\mu_{t}$ is the Lagrangian multiplier for the resource constraints.

Then, the first-order conditions with respect to $G_{t}$ and $K_{t+1}$ imply

$$
V^{\prime}\left(G_{t}\right)=\beta V^{\prime}\left(G_{t+1}\right)\left[M P_{K, t+1}+1-\delta\right] \text {. }
$$

In steady state, government spending, $G_{t}$, is constant by definition. Hence, the steady-state version of equation (5) leads to the MGR.

Proposition $1 \frac{1}{\beta}=M P_{K}+1-\delta$ (the MGR) holds in the optimal steady state.

Proposition 1 states that, in the steady state, pre-tax capital return, $M P_{K}+1-\delta$, must equal the rate of time preference, $1 / \beta$, and characterizes the optimal level of capital stock in the economy. Proposition 1 shows that the Ramsey planner would like to implement the capital stock that satisfies equation (5) regardless of market frictions. In the next section, we show that as long as the pre-tax capital return differs from the time preference rate, there is room for a capital tax or subsidy.

As argued in the introduction, the derivative of equation (5) does not depend on the specific market environment or frictions faced by the households. The optimal choice of aggregate capital has to satisfy the MGR in our generic model. Therefore, the result of the MGR can be extended to a wide range of economies and are not limited to the Aiyagari economy.

\subsection{Optimal Capital Tax}

This section explains our computation of the steady-state capital tax rate. Proposition 1 provides the planner's Euler equation, based on which the planner chooses the optimal level of capital. Equation (2) is the firm's Euler equation, based on which firms make their capital investment decisions in a competitive equilibrium.

The steady-state capital tax rate is chosen such that these two equations become consistent and equivalent to each other:

$$
1=q\left[\left(1-\tau_{K}\right)\left(M P_{K}-\delta\right)+1\right] \equiv \beta\left[M P_{K}+1-\delta\right] .
$$


For the private sector to achieve the optimal capital level in the competitive equilibrium, the optimal capital tax rate should be the following:

$$
\tau_{K}=1-\frac{1 / q-1}{1 / \beta-1},
$$

which leads to the following proposition:

Proposition 2 A positive capital tax is optimal if and only if $R=1 / q<1 / \beta$ in steady state.

Proposition 2 shows that this Ramsey problem yields an outcome (6) of positive capital taxation as long as the market interest rate is lower than the time preference rate in steady state. It is also evident that the Ramsey planner does not consider any effect resulting from the first part of the social welfare function, $W_{0}\left(a_{0}, s_{0},\left\{\bar{w}_{t}\right\}_{t=0}^{\infty},\left\{R_{t}\right\}_{t=0}^{\infty}\right)$, when choosing the optimal capital level. Therefore, the result of equation (6) is general and powerful: As long as a riskfree market interest rate is too low compared with the time discount rate, then the optimal capital tax rate is positive in the steady state. In this sense, the optimal capital taxation question is actually equivalent to the question the asset pricing literature has posed and attempted to answer: Why is the risk-free interest rate too low?

In the next section, we argue that this result-a positive optimal tax rate in the steady state-is derived from one critical assumption: that government spending is endogenously chosen by the Ramsey planner.

\subsection{The Case with Exogenous Government Spending}

We now point out that the MGR does not necessarily hold in an economy without endogenous government spending. Recall that the optimal level of capital stock is decided by the aggregate Euler equation in the Ramsey problem:

$$
\mu_{t}=\beta \mu_{t+1}\left[M P_{K, t+1}+1-\delta\right] .
$$

With endogenous government spending, the Lagrangian multiplier $\mu_{t}$ is obtained by the marginal utility of government spending, such that $\mu_{t}=V^{\prime}\left(G_{t}\right)$, which is identical across all households. Therefore, the MGR holds in steady state given a constant $V^{\prime}\left(G_{t}\right)$. However, in the case of exogenous government spending, there is no guarantee that $\mu_{t}$ should be constant in steady state since the steady state requires that only the ratio $\mu_{t+1} / \mu_{t}$, not the level of $\mu_{t}$ is constant. What is $\mu_{t}$ in this case, then? The value of $\mu_{t}$ is the marginal utility that one extra unit of aggregate consumption can bring to the social welfare, $W_{0}\left(a_{0}, s_{0},\left\{\bar{w}_{t}\right\}_{t=0}^{\infty},\left\{R_{t}\right\}_{t=0}^{\infty}\right)$, which is a complicated object. Hence, the evaluation of $\mu_{t}$ involves the entire distributions of households' consumption and leisure choices.

To demonstrate our argument more clearly, we first use a decentralized economy with limited commitment as an example. In this example, the competitive equilibrium risk-free interest rate could be shown to be lower than the time discount rate. According to our analysis, the capital income should be taxed in the steady state with endogenous government spending. In the exactly identical economy except for exogenous government spending, we then show that the optimal choice of $\mu_{t}$ is not constant in steady state, the MGR is no longer optimal, and the capital tax becomes zero. 


\section{ECONOMY WITH LIMITED COMMITMENT}

In this section, we provide an example showing that the capital taxation result depends critically on the assumption of government spending. With endogenous government spending, the optimal capital tax is positive, while it becomes zero with exogenous government spending.

Consider an economy with complete markets and limited commitment. Households are able to trade a full set of state-contingent claims that provide a hedge to their idiosyncratic shocks; however, the households cannot promise to repay their debts. Upon default, households are excluded from the society and receive an exogenously given autarky value. This example is similar to Park's (2014) benchmark model except for the exogenously given autarky value upon default. We take the particular example economy with limited commitment into consideration for two reasons: (i) Even with a complete asset market, we can have a positive optimal capital tax rate in the steady state with endogenous government spending. And (ii) with endogenous spending, we show that the enforcement constraints in the model economy can result in a low, risk-free interest rate in a competitive equilibrium and hence the optimal capital tax rate is positive as in Aiyagari (1995).

In each period, each agent is endowed with one unit of time and derives a utility from consumption, $c_{t}$, and labor supply, $l_{t}$. We assume that the utility function is separable in consumption and labor:

$$
U\left(c_{t}, l_{t}\right)=u\left(c_{t}\right)-v\left(l_{t}\right)
$$

where $u(\cdot)$ and $v(\cdot)$ are assumed to be bounded, continuously differentiable, strictly increasing, and strictly concave. To facilitate the analysis, we assume the power utility in consumption:

$$
u\left(c_{t}\right)=\frac{1}{1-\gamma} c_{t}^{1-\gamma}
$$

where $\gamma$ is the risk aversion rate.

\subsection{Enforcement Technology}

In this simple example, the autarky value after defaulting is exogenously given, denoted by $\underline{V}_{\text {aut }}$. To keep households from defaulting, we need to ensure that the expected utility of staying in the risk-sharing pool is greater than or equal to the value of defaulting for each possible $s^{t}$. Hence, the enforcement constraints can be written as follows:

$$
\sum_{\tau=t s^{\tau} \geq s^{t}}^{\infty} \beta^{\tau-t} \pi\left(s^{\tau} \mid s^{t}\right)\left[u\left(c_{\tau}\left(s^{\tau}\right)\right)-v\left(l_{\tau}\left(s^{\tau}\right)\right)\right] \geq \underline{V}_{a u t} \text { for } \forall s^{t} .
$$

In other words, if these constraints are satisfied in all states and all periods, households do not wish to exercise their default option. 


\subsection{Competitive Equilibrium}

In this section, we describe details of the household's problem. The firm's problem and the government are the same as in Section 3. The main purpose of this section is to show that the competitive equilibrium risk-free interest rate is lower than the time discount rate, $1 / \beta$.

4.2.1 The Household's Problem. To simplify our analysis, we assume that all households are ex ante identical, meaning that all households are endowed with the same initial asset holding $a_{0}$ and initial shock $s_{0}$. Taking the sequence of after-tax wages $\bar{w}_{t}$ and market interest rates $R_{t}$ as given, a household trades history-contingent consumption claims $\left\{c_{t}\left(s^{t}\right)\right\}$ and makes labor allocation decisions $\left\{l_{t}\left(s^{t}\right)\right\}$ subject to both a lifetime budget constraint and a sequence of enforcement constraints, one for each history:

$$
W_{0}\left(\left\{\bar{w}_{t}\right\}_{t=0}^{\infty},\left\{R_{t}\right\}_{t=0}^{\infty}\right) \equiv \max _{\left\{c_{t}\left(s^{t}\right), l_{t}\left(s^{t}\right)\right\}} \sum_{t=0}^{\infty} \sum_{s^{t}} \beta^{t}\left[u\left(c_{t}\left(s^{t}\right)\right)-v\left(l_{t}\left(s^{t}\right)\right)\right] \pi\left(s^{t}\right)
$$

subject to

$$
\begin{gathered}
\sum_{t=0}^{\infty} \sum_{s^{t}} \prod_{j=1}^{t} \frac{1}{R_{j-1}} \pi\left(s^{t} \mid s_{0}\right)\left[\bar{w}_{t} s_{t} l_{t}\left(s^{t}\right)-c_{t}\left(s^{t}\right)\right] \geq-a_{0} \\
\sum_{\tau=t s^{\tau} \succeq s^{t}}^{\infty} \sum^{\tau-t}\left[u\left(c_{\tau}\left(s^{\tau}\right)\right)-v\left(l_{\tau}\left(s^{\tau}\right)\right)\right] \pi\left(s^{\tau} \mid s^{t}\right) \geq \underline{V}_{a u t} \text { for } \forall s^{t}, t \geq 0,
\end{gathered}
$$

where $\frac{1}{R_{j-1}}=1$. Equation (8) is the present value lifetime budget constraint, and equation (9) is the enforcement constraint.

4.2.2 Equilibrium Prices and Allocations. Let the Lagrangian multipliers for constraints (8) and (9) be $\theta$ and $\beta^{t} \pi\left(s^{t}\right) \mu_{t}\left(s^{t}\right)$, respectively. The household Lagrangian is expressed as the following:

$$
\begin{aligned}
& L=\min _{\theta, \mu_{t}} \max _{c_{t}, l_{t}} \sum_{t} \sum_{s^{t}} \beta^{t} \pi\left(s^{t}\right)\left[u\left(c_{t}\left(s^{t}\right)\right)-v\left(l_{t}\left(s^{t}\right)\right)\right] \\
& +\theta\left[\sum_{t} \sum_{s^{t}} \prod_{j=1}^{t} \frac{1}{R_{j-1}} \pi\left(s^{t}\right)\left[\bar{w}_{t} s_{t} l_{t}\left(s^{t}\right)-c_{t}\left(s^{t}\right)\right]-a_{0}\right] \\
& +\sum_{t} \sum_{s^{t}} \beta^{t} \pi\left(s^{t}\right) \mu_{t}\left(s^{t}\right)\left[\sum_{\tau=t}^{\infty} \sum_{s^{\tau} \succeq s^{t}} \beta^{\tau-t}\left[u\left(c_{\tau}\left(s^{\tau}\right)\right)-v\left(l_{\tau}\left(s^{\tau}\right)\right)\right] \pi\left(s^{\tau} \mid s^{t}\right)-\underline{V}_{a u t}\right] .
\end{aligned}
$$

Following the cumulative Lagrangian method of Marcet and Marimon (1998), the Lagrangian $L$ can be rewritten as

$$
\begin{aligned}
& L=\min _{\theta, \zeta_{t}} \max _{c_{t}, l_{t}} \sum_{t} \sum_{s^{t}} \beta^{t} \pi\left(s^{t}\right)\left[\zeta_{t}\left(s^{t}\right)\left[u\left(c_{t}\left(s^{t}\right)\right)-v\left(l_{t}\left(s^{t}\right)\right)\right]+\left(1-\zeta_{t}\left(s^{t}\right)\right) \underline{V}_{a u t}\right] \\
& +\theta\left[\sum_{t} \sum_{s^{t}} \prod_{j=1}^{t} \frac{1}{R_{j-1}} \pi\left(s^{t}\right)\left[\bar{w}_{t} s_{t} l_{t}\left(s^{t}\right)-c_{t}\left(s^{t}\right)\right]-a_{0}\right],
\end{aligned}
$$




\section{Chien and Lee}

where the cumulative multipliers, $\underline{6} \xi_{t}\left(s^{t}\right)$, can be defined recursively by the following:

$$
\begin{aligned}
& \zeta_{t}\left(s^{t}\right)=\zeta_{t-1}\left(s^{t-1}\right)+\mu_{t}\left(s^{t}\right), \\
& \zeta_{0}\left(s_{0}\right)=1 .
\end{aligned}
$$

Obviously, $\zeta_{t}\left(s^{t}\right)$ is a cumulative sum of all Lagrangian multipliers in the history from enforcement constraints and it encodes the frequency and severity of the binding constraints. In addition, note that $\left\{\zeta_{t}\left(s^{t}\right)\right\}$ is a non-decreasing stochastic process since $\mu_{t}\left(s^{t}\right) \geq 0$.

The first-order condition with respect to $c_{t}\left(s^{t}\right)$ is

$$
\beta^{t} \zeta_{t}\left(s^{t}\right) c_{t}\left(s^{t}\right)^{-\gamma}=\theta \prod_{j=1}^{t} \frac{1}{R_{j-1}},
$$

where $R_{t}$ is the market interest rate faced by all households. $\zeta_{t}\left(s^{t}\right)$ can be viewed as a summary statistic of a household's history measuring how severely and how often the household has been constrained in the past. Therefore, equation (10) implies that (i) a household's consumption is history dependent and (ii) a household should have a higher consumption level if its $\xi_{t}$ value is higher.

Following Chien and Lustig (2010), the consumption-sharing rule can be derived by the first-order condition with respect to consumption-i.e., equation (10) - by the following steps. First, take the ratio of any two individuals' equation (10). Given that the left-hand side of equation (10) is identical across households, the ratio is

$$
\frac{\xi_{t}\left(\hat{s}^{t}\right) c_{t}\left(\hat{s}^{t}\right)^{-\gamma}}{\xi_{t}\left(s^{t}\right) c_{t}\left(s^{t}\right)^{-\gamma}}=1
$$

Second, express the consumption ratio by moving the cumulative multiplier to the right-hand side of the above equation:

$$
\frac{c_{t}\left(\hat{s}^{t}\right)}{c_{t}\left(s^{t}\right)}=\frac{\zeta_{t}\left(\hat{s}^{t}\right)^{\frac{1}{\gamma}}}{\zeta_{t}\left(s^{t}\right)^{\frac{1}{\gamma}}} .
$$

Finally, summing across all possible $\hat{s}^{t}$ gives the consumption-sharing rule:

$$
c_{t}\left(s^{t}\right)=\frac{\zeta_{t}\left(s^{t}\right)^{\frac{1}{\gamma}}}{H_{t}} C_{t},
$$

where

$$
H_{t}=\sum_{s^{t}} \zeta_{t}\left(s^{t}\right)^{\frac{1}{\gamma}} \pi\left(s^{t}\right)
$$

$H_{t}$ is a specific moment of the Lagrange multiplier at period $t$. Note that $H_{t}$ is a non-decreasing process because of the non-decreasing property of $\zeta_{t}\left(s^{t}\right)$. Moreover, $H_{t}$ is a strictly increasing process as long as there is a nonzero fraction of populations who switch to binding enforcement constraints each period. 
The first-order condition (10) implies that the ratio of marginal utilities in consecutive nodes $\left(s^{t}, s^{t+1}\right)$ satisfies the following restriction:

$$
\begin{aligned}
& q_{t}=\frac{1}{R_{t}}=\beta \frac{u_{c, t+1}}{u_{c, t}} \frac{\zeta_{t+1}}{\zeta_{t}} \\
& =\beta\left(\frac{C_{t+1}}{C_{t}}\right)^{-\gamma}\left(\frac{H_{t+1}}{H_{t}}\right)^{\gamma},
\end{aligned}
$$

where the last equality holds by using the consumption-sharing rule in equation (11).

The competitive equilibrium is defined in a similar fashion as in Section 3. The next proposition states that the risk-free rate has to be lower than $1 / \beta$ if there is no full risk sharing.

Proposition $3 \beta<q$ in the steady state, if and only iffull risk sharing is not feasible.

Proof In steady state, equation (12) is simplified to

$$
q=\beta\left(\frac{H_{t+1}}{H_{t}}\right)^{\gamma} .
$$

Given that full risk sharing is not feasible, $H_{t}$ has to be an increasing sequence since a positive fraction of the population features $\zeta_{t+1}\left(s^{t+1}\right)>\zeta_{t}\left(s^{t}\right)$. As a result, $H_{t+1} / H_{t}>1$, which proves that the time discount factor is smaller than the intertemporal price in the steady state, $\beta<q$.

In this economy, the enforcement constraint, equation (9), is the only friction that prevents households from full risk-sharing. Namely, if there is no full risk-sharing, then a nonzero fraction of households must experience binding enforcement constraints. The binding constraint reflects on the increasing value of cumulative multipliers for those households switching to the binding constraints since their Lagrangian multiplier, $\mu_{t+1}\left(s^{t+1}\right)$, is positive. For those households who do not switch to the binding state, their cumulative multipliers remain unchanged. As a result, the $H_{t+1}$, a specific moment of cumulative multipliers, has to be larger than $H_{t}$. The intuition of Proposition 3 could be understood as follows. In the case of full risk-sharing, the market risk-free rate is equal to the time discount rate $1 / \beta$. In this limited commitment economy, the markets are assumed to be complete, meaning that households could hedge against their income risks. To do so, households borrow from the future highincome state and save to the future low-income state. However, because households cannot commit to repay their debt in the future high-income state, there is an implicit borrowing limit imposed by the enforcement constraints. As a result, the equilibrium interest rate adjusts downward compared with the full risk-sharing case to reflect the implicit borrowing limit.

Armed with the assumption of exogenous government spending, Proposition 2 implies that the long-run optimal capital tax rate should be positive in the decentralized economy with this limited commitment case since $\beta<q$ in the steady state. The tax rate can be obtained as

$$
\tau_{K}=1-\frac{1 / q-1}{1 / \beta-1}>0 .
$$




\subsection{The Ramsey Problem with Exogenous Government Spending}

Our limited commitment economy with exogenous government spending is identical to Park's (2014) benchmark economy with one difference: We assume the exogenous autarky value, while Park's autarky value depends on the equilibrium wage rate, which is indirectly related to the level of capital stock resulting from the complementarity in the production technology. Therefore, the primal approach to the Ramsey problem in Park (2014) can be directly applied to our example.

Park's (2014) corollary 1 suggests a zero optimal Ramsey capital taxation result if the autarky value of default is independent of aggregate capital. In our example, the autarky value is exogenously given and hence independent of the choice of aggregate capital. The capital tax should be zero in our limited commitment economy with exogenous government spending. In lieu of providing the detailed algebra, we provide the economic intuition of such a zero tax result in the following paragraph.

As shown earlier in Section 3, for zero capital taxation to hold in steady state, the optimal aggregate Euler equation chosen by the Ramsey planner has to be consistent with the one implied by the competitive equilibrium. The primal approach to the Ramsey problem still leads to the aggregate Euler equation listed below:

$$
\mu_{t}=\beta \mu_{t+1}\left[M P_{K, t+1}+1-\delta\right]
$$

where $\mu_{t}$ is the shadow price of one extra unit of aggregate consumption faced by the Ramsey planner. In addition, we know that the Ramsey planner has to consider the household's first-order condition in evaluating the value of $\mu_{t}$. An alternative way to interpret the cumulative multiplier on the left-hand side of the first-order condition (10) is through the preference shock. More specifically, the Ramsey planner can view the household's discount factor between period $t$ and period 0 as $\beta^{t} \zeta_{t}\left(s^{t}\right)$ instead of the true discount $\beta^{t}$. Other than the modified discount factor, the competitive equilibrium acts exactly like the one without market friction. Hence, the optimal choice of intertemporal price should be consistent with the economy with a modified discount factor, the one described by Proposition 3. As a result, the prescription of intertemporal prices between Ramsey planner and the competitive equilibrium is identical in our limited commitment economy.

In sum, this example demonstrates that the optimal choice of capital in heterogeneous agent models depends critically on the assumption of endogenous government spending. Without this key assumption, the optimal capital taxation switches from a positive number to zero in steady state.

\section{CONCLUSION}

We conclude this article by discussing the issues relating our results to the actual tax policy. Our study suggests that the fiscal authorities should take these theoretical results with caution when they attempt to implement the actual tax policy in a real economy. Particularly, the policymakers should consider these findings as a general guideline for tax policy design and 
should realize that the policy implications were drawn from a simplified version of our real economy. We learned a few lessons from our analysis. First, as we have shown, the positive capital taxation results obtained by Aiyagari (1995) could be sensitive to a specific assumption, such as whether government spending is endogenous or exogenous in a model. It is indeed debatable whether an economy with endogenous or exogenous government spending better describes the economic reality. Furthermore, the assumption that all households consume and evaluate government service equally seems unrealistic even with public goods and services. If we give up this assumption, then our model should instead assume how government spending is distributed across households and how the Ramsey planner evaluates the social welfare from the individual preference to measure the welfare effect of changing the government expenditure.

Second, the Ramsey approach assumes that the government can levy only a linear tax, which is not true in reality. The U.S. income tax code includes progressivity and nonlinearity in its income tax rates. The optimal taxation results critically depend on the assumption of the implementability of a set of policy tools. If the government can direct an individual household's decision through a nonlinear and individual-specific taxation, the economy may be able to achieve its first-best regardless of market frictions and model environments.

Third, the Ramsey approach assumes the government always commits to its policy, which is also a strong assumption. - The literature on political economics often argues that this is not the case. Furthermore, we do not assume simply that government commits to its tax policy but we also assume that government cannot default on its bonds. The enforceability and availability of government bonds in the Aiyagari model are important. In our thought experiment, the Ramsey planner can freely choose government spending to offset the change in capital investment without violating the government budget constraint since there are government bonds available and the government never defaults on them. Without government bonds or a binding restriction of issuing them, one can actually show the MGR result fails in general.

Finally, a quantitative exercise is essential for a positive optimal capital taxation. Without a carefully calibrated model economy, it is hard to know the actual level of optimal capital taxation. In the economy with government bonds, the asset market clearing condition requires aggregate capital to consist of household savings plus government debt. The market clearing condition implies that the government could lower the capital stock not only by capital taxation but also by increasing government debt. It is possible that, at the optimum, the government has to issue a high amount of government bonds to meet the demand of precautionary savings. A large fraction of precautionary savings could be held by the government in the form of government debt with the result that a relatively small fraction of household savings actually turns into capital. Hence, it is possible that the optimal capital tax is very low or even near zero quantitatively while still positive as implied by the qualitative analysis in this article. 


\section{Chien and Lee}

\section{NOTES}

1 Mirrlees (1971) provides another approach to analyzing the optimal tax policy. Refer to Mankiw, Matthew, and Yagan (2009) for a detail discussion of these two approaches.

$\underline{2}$ The "oversaving" refers to the higher level of savings compared with the level of savings in a frictionless representative agent economy.

3 The position of government bonds does change to satisfy the government budget constraint. Therefore, the existence of government bonds is important to derive the result.

4 For clear exposition, we assume that capital taxes are paid by the firm. Our result does not change if capital taxes are paid by households.

$\underline{5}$ In addition to budget constraints, households could also face constraints on asset holding and asset trading that depend on the market structure in general.

6 We formulate the Lagrangian by using the cumulative multiplier as in Marcet and Marimon (1998).

$\underline{7}$ Martin (2010) shows that in an economy lacking government commitment, the labor and capital income tax rates are more realistic.

\section{REFERENCES}

Aiyagari, S. Rao. "Uninsured Idiosyncratic Risk and Aggregate Saving." Quarterly Journal of Economics, August 1994, 109(3), pp. 659-84; http://dx.doi.org/10.2307/2118417.

Aiyagari, S. Rao. "Optimal Capital Income Taxation with Incomplete Markets, Borrowing Constraints, and Constant Discounting." Journal of Political Economy, December 1995, 103(6), pp. 1158-175; http://dx.doi.org/10.1086/601445.

Atkeson, Andrew; Chari, V.V. and Kehoe, Patrick J. "Taxing Capital Income: A Bad Idea?" Federal Reserve Bank of Minneapolis Quarterly Review, September 1999, 23(3), pp. 3-17; https://www.minneapolisfed.org/research/qr/qr2331.pdf.

Chamley, Christophe. "Optimal Taxation of Capital Income in General Equilibrium with Infinite Lives." Econometrica, May 1986, 54(3), pp. 607-22; http://dx.doi.org/10.2307/1911310.

Chari, V.V. and Kehoe, Patrick J. "Optimal Fiscal and Monetary Policy," in John Taylor and Michael Woodford, eds., Handbook of Macroeconomics. Volume 1C. Chap. 26. New York: Elsevier, 1999, pp. 1673-45.

Chien, YiLi and Lustig, Hanno. "The Market Price of Aggregate Risk and the Wealth Distribution." Review of Financial Studies, April 2010, 23(4), pp. 1596-650; http://dx.doi.org/10.1093/rfs/hhp079.

Diamond, Peter A. and Mirrlees, James A. "Optimal Taxation and Public Production I: Production Efficiency." American Economic Review, March 1971, 61(1), pp. 8-27.

Huggett, Mark. "The Risk-Free Rate in Heterogeneous-Agent Incomplete-Insurance Economies." Journal of Economic Dynamics and Control, September-November 1993, 17(5-6), pp. 953-69; http://dx.doi.org/10.1016/0165-1889(93)90024-M.

Judd, Kenneth L. "Redistributive Taxation in a Simple Perfect Foresight Model." Journal of Public Economics, October 1985, 28(1), pp. 59-83; http://dx.doi.org/10.1016/0047-2727(85)90020-9.

Lucas, Robert E. Jr. "Supply-Side Economics: An Analytical Review." Oxford Economics Papers, April 1990, 42(2), pp. 293-316.

Mankiw, N. Gregory; Weinzierl, Matthew and Yagan, Danny. "Optimal Taxation in Theory and Practice." Journal of Economic Perspectives, Fall 2009, 23(4), pp. 147-74; http://dx.doi.org/10.1257/jep.23.4.147.

Marcet, Albert and Marimon, Ramon. "Recursive Contracts." Working Paper No. 337, Universitat Pompeu Fabra, October 1998; http://www.econ.upf.edu/docs/papers/downloads/337.pdf.

Martin, Fernando M. "Markov-Perfect Capital and Labor Taxes." Journal of Economic Dynamics and Control, March 2010, 34(3), pp. 503-21; http://dx.doi.org/10.1016/j.jedc.2009.10.006. 


\section{Chien and Lee}

Mirrlees, J.A. "An Exploration in the Theory of Optimal Income Taxation." Review of Economic Studies, April 1971, 38(2), pp. 175-208; http://dx.doi.org/10.2307/2296779.

Park, Yena. "Optimal Taxation in a Limited Commitment Economy." Review of Economic Studies, April 2014, 81(2), pp. 884-918; http://dx.doi.org/10.1093/restud/rdt038.

Ramsey, F.P. "A Contribution to the Theory of Taxation." Economic Journal, March 1927, 37(145), pp. 47-61; http://dx.doi.org/10.2307/22222721. 
